\title{
The relation between dermoscopy and histopathology of basal cell carcinoma*
}

\author{
Nazan Emiroglu ${ }^{1}$ \\ Funda Kemeriz ${ }^{2}$
}

\author{
Fatma Pelin Cengiz ${ }^{1}$
}

DOI: http:/ /dx.doi.org/10.1590/abd1806-4841.20153446

\begin{abstract}
A bstract: BACKGROUND: Basal cell carcinoma is the most frequent cancer in fair-skinned populations and dermoscopy is an important, non-invasive technique that aids in the diagnosis of Basal cell carcinoma.

Oвjестіves: The aim of this study was to evaluate the relationship between histopathological subtypes and dermoscopic features of Basal cell carcinoma.

Methods: This study included 98 patients with clinically and histopathologically confirmed Basal cell carcinomas. The dermoscopic features of the lesions from each patient were analyzed before the histopathological findings were evaluated.

RESULTS: Dermoscopic structures were observed in all 98 patients and irregular vascularity was identified in 78 patients $(79.6 \%)$. The most common vascular pattern was the presence of arborizing vessels (42 patients, $42.9 \%$ ) followed by arborizing microvessels (21 patients, 21.4\%) and short fine telangiectasias (SFTs; 15 patients, 15.3\%). White streaks (38 patients, 38.8\%), translucency (31 patients, 31.6\%), a milky-pink to red background (42 patients, $42.9 \%$ ), and erosion/ulceration (29 patients, $29.6 \%$ ) were also observed. Pigmented islands were seen as blue-gray globules (7 patients, $7.1 \%$ ) and blue-gray ovoid nests (42 patients, $42.9 \%)$. The pigment distribution pattern was maple leaf-like areas in 9 patients $(9.2 \%)$ and spoke wheel-like areas in 6 patients $(6.1 \%)$.

Conclusions: Basal cell carcinomas show a wide spectrum of dermoscopic features. Arborizing vessels were the most common dermoscopic findings in Basal cell carcinomas, while superficial Basal cell carcinomas displayed mainly milky-pink to red areas, and arborizing microvessels. The most common dermoscopic features of pigmented types were islands of pigment (blue-gray globules, blue-gray ovoid nests). In conclusion, dermoscopy can be used as a valuable tool for the diagnosis of Basal cell carcinomas and prediction of their histopathological subtypes.
\end{abstract}

Keywords: Carcinoma, basal cell; Dermoscopy; Neoplasms, basal cell

\section{INTRODUCTION}

Non-melanoma skin cancer (NMSC) is the most common cancer in humans, and approximately $75-80 \%$ of NMSCs are Basal Cell Carcinomas (BCCs). BCC usually affects fair-skinned individuals over 40 years of age, most often on the head and neck, which are chronically exposed to the sun. Ultraviolet type B (UV-B) radiation is the most important environmental factor that leads to BCC via the silencing of tumor suppressor genes. BCCs rarely metastasize and thus rarely lead to death, but can result in significant morbidity if not promptly diagnosed and managed. No universally accepted classification exists for BCCs, and many different subtypes have been described.
Attempts have been made to classify lesions based on growth patterns or along lines of differentiation, but this has not gained universal acceptance. Variants of BCC include nodular, superficial, morpheaform, cystic, basosquamous, micronodular, and fibroepithelioma of Pinkus. ${ }^{1,2}$

The diagnosis of BCC is made clinically, based on the finding of suspicious lesions, and then verified by biopsy and histopathology. While biopsy is a timeconsuming and costly method, ${ }^{3,4}$ dermoscopy is an inexpensive, in vivo, non-invasive method which allows the examination of morphologic features that are not visible to the naked eye. ${ }^{5}$ Importantly, it also allows the 
early diagnosis of melanoma, and plays an important role in the clinical assessment of BCC. ${ }^{6-10}$ However, an examination of the association between the dermoscopic and histopathological features of BCCs has not yet been undertaken. ${ }^{11}$ Therefore, the aim of this study was to investigate the relationship between dermoscopy and histopathology in BCCs.

\section{MATERIALS AND METHODS}

This observational, morphological study involved 98 patients with BCC and was approved by the Kutahya Tavsanli State Hospital Ethics Committee. Informed consent was received from all participants. Dermoscopic images were captured using a DermLite Foto polarized light dermatoscope and a Canon PowerShot A630 digital camera. Clinical and dermoscopic images were assessed by three expert dermatologists using predefined criteria from the literature. The localization and diameter of the lesion, histological subtype of the lesion, dermoscopic patterns, Fitzpatrick skin type and sex of each patient were recorded (Table 1). Dermoscopic features were divided into nine groups (irregular vascular pattern, white areas, translucency, milky-pink to red background, erosion/ulceration, blue-gray globules, blue-gray ovoid nests, maple leaf-like areas and spoke wheel-like areas). Definitions of these criteria are provided in table 2 . The relationship between localization and type of BCCs is shown in table 3.

\section{RESULTS}

\section{Clinicopathological Features}

This study involved 98 patients (62 male and 36 female) with BCC. The mean age of the patients was $64.05 \pm 14.11$ years. Forty-nine patients $(50 \%)$ had Fitzpatrick skin type I, 37 (37.8\%) had skin type II, and $12(12.2 \%)$ had skin type III. The most common type of BCC was nodular BCC (37 patients, 37.8\%), followed by mixed BCC (24 patients, $24.5 \%$ ), superficial BCC (19 patients, 19.4\%), morpheaform BCC (15 patients, $15.3 \%)$, and pigmented BCC (3 patients, 3.1\%)(Table 1 ).

The most frequent location of the lesions was the head and neck (43 patients, $43.9 \%$ ) and the trunk (40 patients, $40.8 \%$ ). Other locations included the lower extremity (12 patients, $12.2 \%$ ) and the upper extremities (3 patients, 3.1\%) (Table 3).

The mean diameter of the lesions was $7.05 \pm 3.50$ $\mathrm{mm}$. All of the lesions were excised and underwent a histopathological examination.

\section{Dermoscopic Features}

The dermoscopic features observed in this study were as follows: a milky-pink to red background (42 patients, 42.9\%), white streaks (38 patients, 38.8\%), translucency (31 patients, 31.6\%), and erosion/ ulceration (29 patients, 29.6\%). Pigmented islands were seen as blue-gray globules (7 patients, $7.1 \%$ ) and bluegray ovoid nests (42 patients, $42.9 \%$ ). The distribution pattern of the pigmentation was maple leaf-like areas in 9 patients $(9.2 \%)$ and spoke wheel-like areas in 6 patients $(6.1 \%)$. Irregular vascularity was observed in 78 patients $(79.6 \%)$. The most common vascular pattern was the presence of arborizing vessels (42 patients, $42.9 \%$ ) followed by arborizing microvessels (21 patients, $21.4 \%$ ) and SFTs (15 patients, $15.3 \%$ ). (Table 2)

Associations between each of the above parameters were evaluated. There was a positive correlation between the diameter of lesion and the age of patients ( $p<0.001, r=+0.352)$, as well as a positive correlation between the diameter of the lesion and the presence of blue-gray ovoid nests $(p<0.001, r=$ $+0.455)$. There was a negative correlation between the age of patients and the presence of SFTs $(p<0.001, r$ $=-0.393$ ). There was also a strong positive association between the presence of blue-gray ovoid nests and spoke wheel-like structures $(\mathrm{p}=0.001, \mathrm{r}=0.338)$.

TABLE 1: Dermoscopic patterns, age of patients, skin type of Fitzpatrick, localization, diameter and histological subtypes

\begin{tabular}{|c|c|c|}
\hline \multirow{2}{*}{$\begin{array}{l}\text { Clinical D ata } \\
\text { Age }\end{array}$} & \multicolumn{2}{|c|}{ Basal Cell Carcinoma } \\
\hline & Female & Male \\
\hline$<20$ years & - & - \\
\hline 21- 40 years & $3(8.3 \%)$ & $3(4.8 \%)$ \\
\hline 41- 60 years & $21(58.3 \%)$ & $12(19.4 \%)$ \\
\hline$>60$ years & $12(33.3 \%)$ & $47(75.8 \%)$ \\
\hline \multicolumn{3}{|l|}{ Histological Type } \\
\hline Superficial & $9(25 \%)$ & $10(16.1 \%)$ \\
\hline Nodular & $13(36.1 \%)$ & $24(38.7 \%)$ \\
\hline Morpheaform & $6(16.7 \%)$ & $9(14.5 \%)$ \\
\hline Pigmented & - & $3(4.8 \%)$ \\
\hline Mixed & $8(22.2 \%)$ & $16(25.8 \%)$ \\
\hline \multicolumn{3}{|l|}{ Diameter } \\
\hline$<5 \mathrm{~mm}$ & $18(50.0 \%)$ & $15(24.2 \%)$ \\
\hline 5- $10 \mathrm{~mm}$ & $12(33.3 \%)$ & $44(71.0 \%)$ \\
\hline $10-15 \mathrm{~mm}$ & $3(8.3 \%)$ & - \\
\hline $15-20 \mathrm{~mm}$ & $3(8.3 \%)$ & $3(4.8 \%)$ \\
\hline \multicolumn{3}{|l|}{ Location } \\
\hline Trunk & $12(33.3 \%)$ & $28(45.2 \%)$ \\
\hline Head and Neck & $18(50.0 \%)$ & $25(40.3 \%)$ \\
\hline Lower extremity & $6(16.7 \%)$ & $6(9.7 \%)$ \\
\hline Upper extremity & - & $3(4.8 \%)$ \\
\hline \multicolumn{3}{|c|}{ Skin Type of Fitzpatrick } \\
\hline 1 & $21(58.3 \%)$ & $28(45.2 \%)$ \\
\hline 2 & $12(33.3 \%)$ & $25(40.3 \%)$ \\
\hline 3 & $3(8.3 \%)$ & $9(14.5 \%)$ \\
\hline
\end{tabular}


Table 2: Dermoscopic Features of BCCs

\begin{tabular}{llllll}
\hline D ermoscopic Features & Superficial & N odular & M orpheaform & Pigmented & M ixed \\
\hline Irregular V ascular Pattern & $16(20.5 \%)$ & $28(35.9 \%)$ & $12(15.4 \%)$ & $1(1.3 \%)$ & $21(26.9 \%)$ \\
Arborizing Vessels & $0(0.0 \%)$ & $22(52.4 \%)$ & $6(14.3 \%)$ & $1(2.4 \%)$ & $13(31.0 \%)$ \\
Short fine telangiectasias & $6(40.0 \%)$ & $3(20.0 \%)$ & - & - & $6(40.0 \%)$ \\
Arborizing microvessels & $10(47.6 \%)$ & $3(14.3 \%)$ & $6(28.6 \%)$ & - & $2(9.5 \%)$ \\
White Streaks/White structures & $3(7.9 \%)$ & $15(39.5 \%)$ & $5(13.2 \%)$ & - & $15(39.5 \%)$ \\
Translucency & - & $19(61.3 \%)$ & $9(29.3 \%)$ & - & $3(9.7 \%)$ \\
Milky-pink to red background & $19(45.2 \%)$ & $9(21.4 \%)$ & $6(14.3 \%)$ & - & $8(19.0 \%)$ \\
Erosion & $4(13.8 \%)$ & $13(44.8 \%)$ & $3(10.3 \%)$ & - & $9(31.0 \%)$ \\
Blue-gray globules & $2(28.6 \%)$ & - & $2(28.6 \%)$ & $3(42.9 \%)$ & - \\
Blue-gray ovoid nests & - & $12(28.6 \%)$ & $9(21.4 \%)$ & - & $21(50 \%)$ \\
M aple-leaf like Structures & - & $1(11.1 \%)$ & - & $2(22.2 \%)$ & $6(66.7 \%)$ \\
Spoke wheel-like Structures & - & - & - & $3(50 \%)$ & $3(50 \%)$ \\
\hline
\end{tabular}

TABLE 3: Relation between Localization and Type of BCC

\begin{tabular}{llllll}
\hline Location & Nodular & Superficial & Morpheaform & Pigmented & Mixed \\
\hline Head and Neck & $28(75.7 \%)$ & $4(21.1 \%)$ & $6(40.0 \%)$ & $3(100 \%)$ & $3(12.5 \%)$ \\
Trunk & $3(8.1 \%)$ & $12(63.2 \%)$ & $6(40.0 \%)$ & - & $18(75 \%)$ \\
Upper ext & $3(8.1 \%)$ & - & - & - & - \\
Lower ext & $3(\% 8.1 \%)$ & $3(15.8 \%)$ & $3(20.0 \%)$ & - & $3(12.5 \%)$ \\
\hline
\end{tabular}

\section{DISCUSSION}

Dermoscopy has been shown to be valuable in the diagnosis of pigmented skin lesions. Recently a few reports have been published that have suggested an algorithm for the dermoscopic diagnosis of nonpigmented skin cancers.

In this study, we investigated the dermoscopic and histopathological variability of BCCs in order to aid in their diagnosis. Patients (98 in total) were classified into groups according to histopathological subtype (37 nodular, 19 superficial, 15 morpheaform, 3 pigmented, and 24 mixed), and dermoscopic findings were recorded.

The most common type of BCCs found were nodular BCCs (37 patients, 37.8\%), which were localized mainly in the head and neck. The ratio of females to males with these lesions was $1 / 2$. The most common dermoscopic pattern seen in nodular BCCs was irregular vascularity (28 patients, $75.7 \%$ ), and, in $22(78.6 \%)$ of these patients, arborizing vessels $(>0.2 \mathrm{~mm}$ in diameter) were the most frequent irregular vascular pattern. The second most common dermoscopic finding in patients with nodular BCCs was translucency (19 patients, $51.4 \%$ ).

Overall, arborizing vessels were seen in 42 $(42.9 \%) \mathrm{BCCs}$, and were significantly more common in nodular BCCs (22/37; 78.6\%). Arborizing telangectasias and SFTs represented the second most common vascular pattern, and were more frequent in superficial BCCs $(16 / 19 ; 84.2 \%)$ (Figures 1-4). The presence of at least one irregular vascular pattern was detected in a total of 78 patients $(79.5 \%)$. The findings of our study resemble those of Micantonio et al., who analyzed 504 cases of BCC and detected at least one vascular pattern in $91.5 \%$ of cases. ${ }^{12}$ They compared vascular patterns of BCCs and showed that arborizing vessels were significantly more frequent in nodular BCCs compared

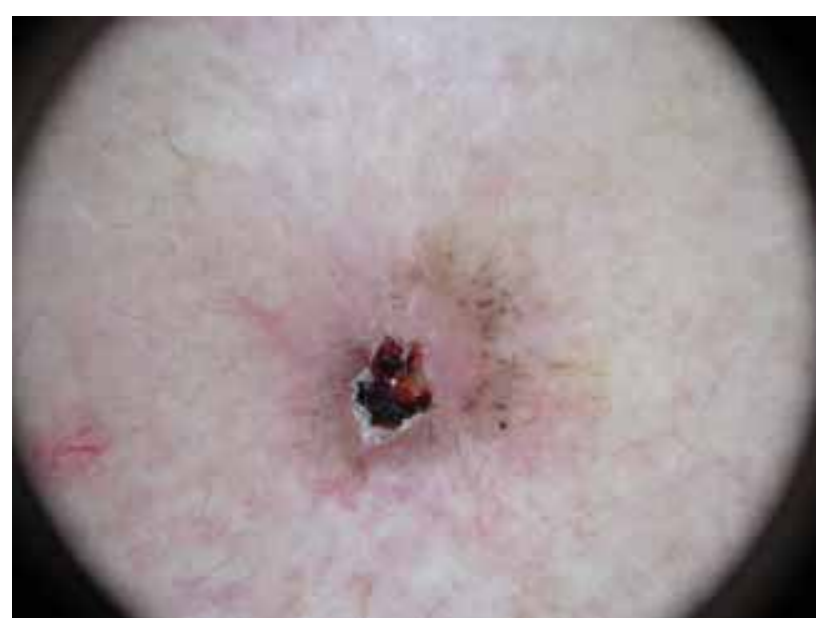

FigURA 1: Erosion/ulceration and blue-gray globules 


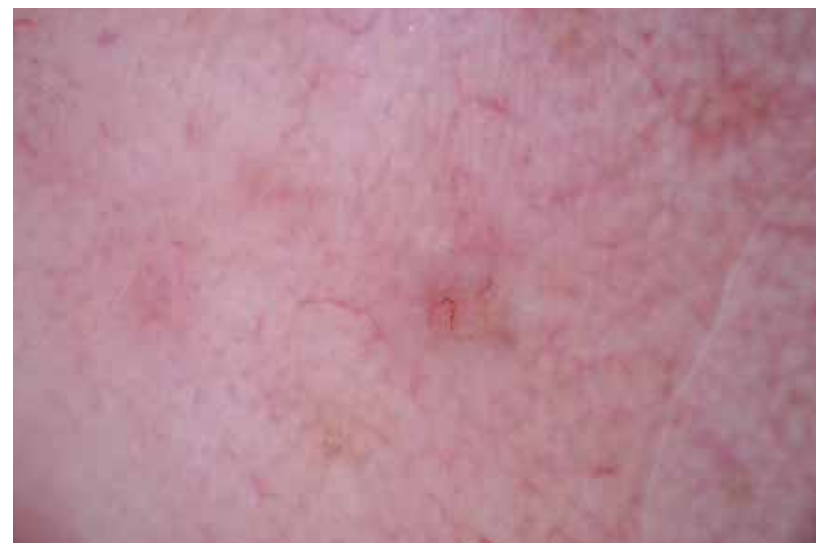

FIGURA 2: Arborizing microvessels, translucency

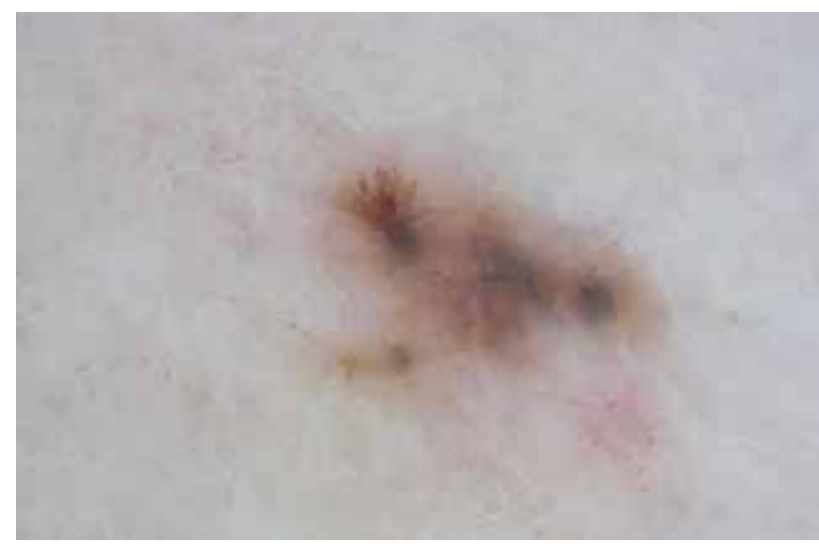

FIgura 3: Maple Leaf-like Areas

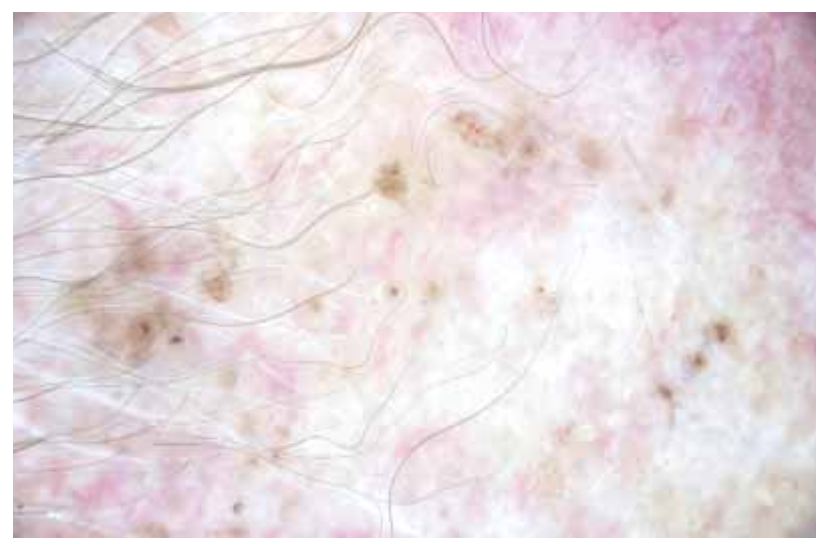

FIgura 4: Spoke Wheel-like Areas

with superficial BCCs, whereas SFTs were significantly more common in superficial BCCs compared with nodular BCCs. They suggested that this might be due to an increased need for blood in nodular BCCs, when compared with superficial BCCs. ${ }^{12}$
In our study, superficial BCCs were observed in 19 patients (19.4\%), and many of these were located on the trunk. The ratio of females to males with these lesions was 1.0. All cases of superficial BCCs had a milky-pink to red background (19 patients, $100 \%$ ), and irregular vascular patterns were recorded in 16 lesions $(84.2 \%)$.

The diameter of the arborizing vessels seen in superficial BCCs were smaller than those seen in nodular BCCs $(<0.2 \mathrm{~mm})$. These were termed as arborizing telangiectasias and were observed in 10 patients (52.6\%). There were no arborizing vessels with a diameter $>0.2 \mathrm{~mm}$. In addition, SFTs were present in 6 cases $(31.6 \%)$

A recent study evaluating 42 cases of superficial BCCs revealed milky-pink to red background areas in $100 \%$ of lesions, and 33 lesions (78.6 \%) also showed erosions. ${ }^{13}$ SFTs were observed in 28 lesions $(66.6 \%)$, and arborizing telangiectasias $(<0.2 \mathrm{~mm}$ in diameter $)$ were detected in 6 cases $(14.3 \%)$. In addition, 14 superficial BCCs presented at least one Menzies criteria. ${ }^{13}$ Our results confirm the presence of milky-pink to red background areas in 100\% of superficial BCC lesions. However, we found erosions in only $21.1 \%$ of lesions and SFTs in only $31.6 \%$ of lesions. In another study by Giacomel et al., ${ }^{14}$ milky-pink to red background areas were noted in $100 \%$ of superficial BCCs, while $92 \%$ displayed SFTs. Erosions/ulcerations were observed in $71 \%$ and long arborizing vessels were seen in $8 \%$ of these lesions. ${ }^{14}$

In this study, the histopathological subtypes of the lesions in 15 patients were morpheaform. In these, irregular vascular patterns were seen in $80 \%$ of cases $(6$ cases with arborizing vessels, 6 cases with arborizing telangiectasias). Translucency was observed in 9 patients $(60 \%)$ and blue-gray ovoid nests were noted in 9 patients $(60 \%)$ (Figures 1, 3, 5).

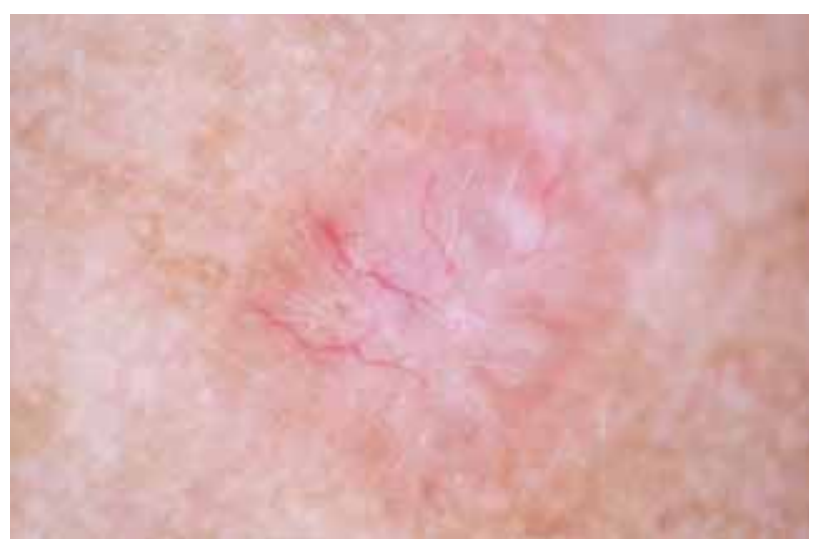

Figura 5: Arborizing Vessels 
This study included $3(3.1 \%)$ cases with pigmented BCCs. Blue-gray globules and spoke wheel-like areas were observed in all of these lesions, while 2 lesions had maple leaf-like structures and 1 lesion had arborizing vessels (Figures 6,7). While these 3 patients are not a large enough sample to provide statistical significance, it is interesting to note that, in our study, many of the patients with mixed BCCs (17/24 patients) also displayed a pigmented subtype.

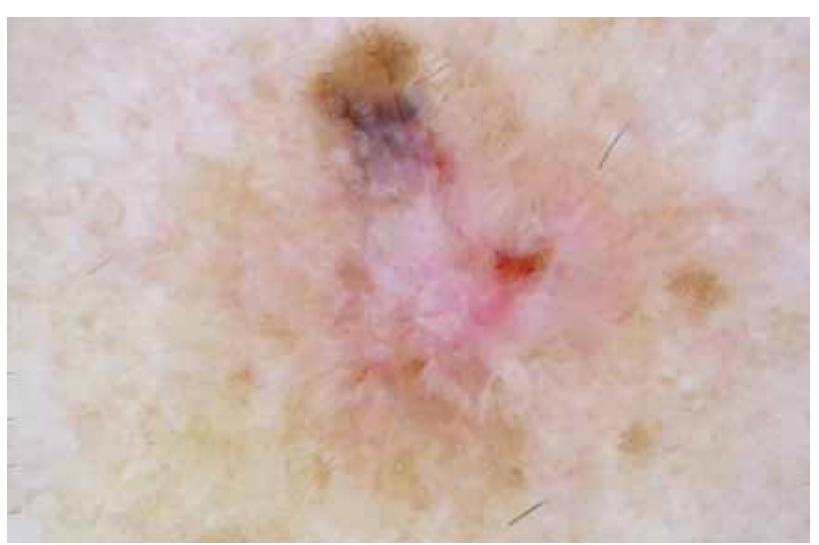

FIGURA 6: White structures, short fine telengiectasias, and blue-gray areas

The most common dermoscopic features of these pigmented variants were as follows: pigmented islands (35.3\% of cases, with blue-gray globules in one patient and blue-gray ovoid nests in five patients); a pigmented distribution pattern $(17.6 \%$ of cases, with maple leaflike structures in 2 patients and spoke wheel-like areas in 1 patient); arborizing vessels (23.5\% of cases); and white streaks/white areas (23.5\% of cases).

Dermoscopic features of pigmented BCCs were first reported by Puspok-Schwarz et al. ${ }^{15}$ In this report, dermoscopic features from 25 pigmented BCCs were compared with 25 melanomas. Arborizing telangiectasias were found in $52 \%$ of pigmented BCCs, and described as the strongest model for diagnosis. ${ }^{15} \mathrm{In}$ our study, arborizing vessels were found in $33.3 \%$ of pigmented BCCs, and in $23.5 \%$ of pigmented subtypes

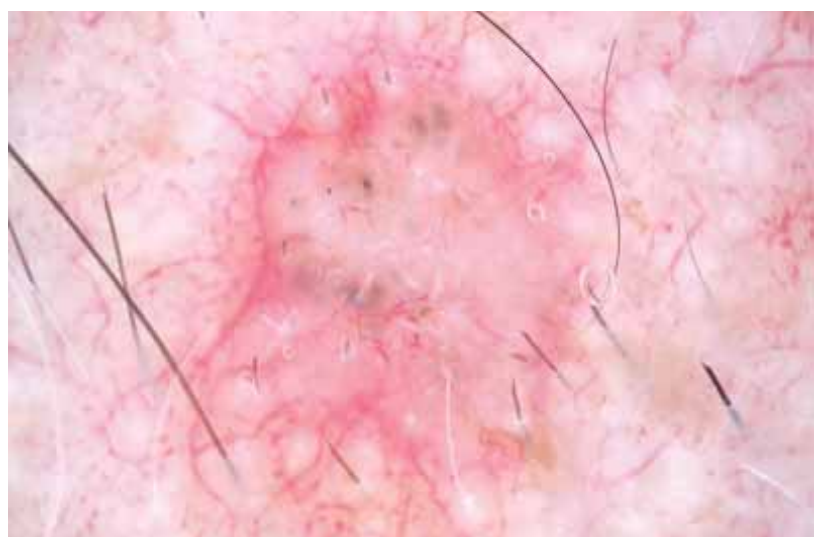

FIgURA 7: Arborizing microvessels, arborizing vessels, and short fine telengiectasias

of mixed BCCs. In 2005, Menzies et al. ${ }^{16}$ defined dermoscopic features of pigmented BCCs. They suggested a dermoscopic model for the diagnosis of pigmented BCCs, based on the absence of a pigment network (negative feature) and the presence of at least one of the dermoscopic features (positive feature) defined as follows: arborizing telangiectasias (52\%), large grey-blue ovoid nests $(55 \%)$, multiple greyblue globules $(27 \%)$, ulceration $(27 \%)$, maple leaflike areas $(17 \%)$, spoke wheel-areas $(10 \%)$. In our study, dermoscopic features of pigmented BCCs were provided using these criteria. ${ }^{16}$

\section{CONCLUSION}

This study has described a wide spectrum of dermoscopic features of BCCs according to their histopathological subtypes. The presence of arborizing vessels is the most common dermoscopic finding in BCCs, and these were most often seen in nodular BCCs. Milky-pink to red areas, arborizing microvessels and SFTs are the most common features in superficial BCCs. Pigmented islands (blue-gray globules and, blue-gray ovoid nests) are the most common features of pigmented BCCs. Our results suggest that dermoscopy may provide an indication of the histopathological subtypes of BCCs.] 


\section{REFERENCE}

1. Roewert-Huber J, Lange-Asschenfeldt B, Stockfleth E, Kerl H. Epidemiology and etiology of basal cell carcinoma. Br J Dermatol. 2007;157:47-51.

2. Leiter U, Garbe C. Epidemiology of melanoma and nonmelanoma skin cancer-the role of sunlight. Adv Exp Med Biol. 2008;624:89-103.

3. Hallock GG, Lutz DA. Prospective study of the accuracy of the surgeon's diagnosis in 2000 excised skin tumors. Plast Reconstr Surg. 1998;101:1255-61.

4. Marghoob AA, Swindle LD, Moricz CZ, Sanchez Negron FA, Slue B, Halpern AC, et al. Instruments and new technologies for the in vivo diagnosis of melanoma. J Am Acad Dermatol. 2003;49:777-97.

5. Zalaudek I, Argenziano G, Di Stefani A, Ferrara G, Marghoob AA, HofmannWellenhof $R$, et al. Dermoscopy in general dermatology. Dermatology. 2006;212:7-18

6. Bafounta ML, Beauchet A, Aegerter P, Saiag P. Is dermoscopy (epiluminescence microscopy) useful for the diagnosis of melanoma? Results of a meta-analysis using techniques adapted to the evaluation of diagnostic tests. Arch Dermatol. 2001; 137:1343-50

7. Kittler $\mathrm{H}$, Pehamberger $\mathrm{H}$, Wolff K, Binder M. Diagnostic accuracy of dermoscopy. Lancet Oncol. 2002;3:159-65.

8. Zalaudek I, Argenziano G, Di Stefani A, Ferrara G, Marghoob AA, HofmannWellenhof $R$, et al. Dermoscopy in general dermatology. Dermatology. 2006;212:7-18

9. Vestergaard ME, Macaskill P, Holt PE, Menzies SW. Dermoscopy compared with naked eye examination for the diagnosis of primary melanoma: a meta-analysis of studies performed in a clinical setting. Br J Dermatol. 2008;159:669-76.

10. Micali G, Lacarrubba F, Massimino D, Schwartz RA. Dermatoscopy: alternative uses in daily clinical practice. J Am Acad Dermatol. 2011;64:1135-46.

11. Cabrijan L, Lipozencić J, Batinac T, Lenković M, Gruber F, Stanić Zgombić Z. Correlation between clinical-dermatoscopic and histopathologic diagnosis of skin tumors in our patients. Coll Antropol. 2008;32:195-7.

12. Micantonio T, Gulia A, Altobelli E, Di Cesare A, Fidanza R, Riitano A, et al. Vascular patterns in basal cell carcinoma J Eur Acad Dermatol Venereol. 2011;25:358-61.

13. Scalvenzi M, Lembo S, Francia MG, Balato A. Dermoscopic patterns of superficial basal cell carcinoma. Int J Dermatol. 2008;47:1015-8.

14. Giacomel J, Zalaudek I. Dermoscopy of superficial basal cell carcinoma. Dermatol Surg. 2005;31:1710-3.

15. Püspök-Schwarz M, Steiner A, Binder M, Partsch B, Wolff K, Pehamberger $H$. Statistical evaluation of epiluminescence microscopy criteria in the differential diagnosis of malignant melanoma and pigmented basal cell carcinoma. Melanoma Res. 1997;7:307-11.

16. Menzies SW, Westerhoff K, Rabinovitz H, Kopf AW, McCarthy WH, Katz B. Surface microscopy of pigmented basal cell carcinoma. Arch Dermatol. 2000;136:1012-6.
M AILING ADDRESS:

$\mathrm{N}$ azan Emiroglu

Istasyon Cad.yeni M ah.31/11 - Tavsanli

Kutahya -Turquia.

E-mail: dr.nazanyilmaz@hotmail.com

How to cite this article: Emiroglu N, Cengiz FP, Kemeriz F. The relation between dermoscopy and histopathology of basal cell carcinoma. An Bras Dermatol. 2015;90(3):351-6. 